ARTICLE

Received 15 Dec 2014 | Accepted 23 Apr 2015 | Published 1 Jun 2015

DOI: $10.1038 /$ ncomms 8271

OPEN

\title{
Cooperative folding of intrinsically disordered domains drives assembly of a strong elongated protein
}

Dominika T. Gruszka ${ }^{1, \star}$, Fiona Whelan ${ }^{2, \star}$, Oliver E. Farrance ${ }^{3}$, Herman K.H. Fung ${ }^{2}$, Emanuele Paci ${ }^{3}$, Cy M. Jeffries ${ }^{4}$, Dmitri I. Svergun ${ }^{4}$, Clair Baldock ${ }^{5}$, Christoph G. Baumann ${ }^{2}$, David J. Brockwell ${ }^{3}$, Jennifer R. Potts ${ }^{2} \&$ Jane Clarke ${ }^{1}$

Bacteria exploit surface proteins to adhere to other bacteria, surfaces and host cells. Such proteins need to project away from the bacterial surface and resist significant mechanical forces. Sas is a protein that forms extended fibrils on the surface of Staphylococcus aureus and promotes host adherence and biofilm formation. Here we show that although monomeric and lacking covalent cross-links, SasG maintains a highly extended conformation in solution. This extension is mediated through obligate folding cooperativity of the intrinsically disordered $\mathrm{E}$ domains that couple non-adjacent $\mathrm{G} 5$ domains thermodynamically, forming interfaces that are more stable than the domains themselves. Thus, counterintuitively, the elongation of the protein appears to be dependent on the inherent instability of its domains. The remarkable mechanical strength of SasG arises from tandemly arrayed 'clamp' motifs within the folded domains. Our findings reveal an elegant minimal solution for the assembly of monomeric mechano-resistant tethers of variable length.

\footnotetext{
${ }^{1}$ Department of Chemistry, University of Cambridge, Lensfield Road, Cambridge CB2 1EW, UK. ${ }^{2}$ Department of Biology, University of York, Wentworth Way, York Y010 5DD, UK. ${ }^{3}$ Astbury Centre for Structural Molecular Biology, University of Leeds, Leeds LS2 9JT, UK. ${ }^{4}$ European Molecular Biology Laboratory, Hamburg Unit, Notkestrasse 85, 22603 Hamburg, Germany. ${ }^{5}$ Faculty of Life Sciences, Wellcome Trust Centre for Cell-Matrix Research, University of Manchester, Michael Smith Building, Greater Manchester M13 9PT, UK. * These authors contributed equally to this work. Correspondence and requests for materials should be addressed to J.R.P. (email: jennifer.potts@york.ac.uk) or to J.C. (email: jc162@cam.ac.uk).
} 
acteria adhere to surfaces, host cells and one another via specialized surface proteins (for example, pili, fimbriae or cellulosomes), which need to project away from the bacterial surface and be resistant to mechanical stress ${ }^{1,2}$. The mechanisms commonly used by bacterial adhesins to achieve both extension and mechanical strength are multimeric assembly and/or covalent stabilization ${ }^{1,3-6}$. SasG from Staphylococcus aureus and accumulation-associated protein from S. epidermidis are homologous proteins that promote host colonization and biofilm formation ${ }^{7-9}$. Staphylococcal biofilms are clinically important functional micro-communities of bacteria ${ }^{10}$ that cause hospital-acquired infections ${ }^{11}$ and promote exchange of antibiotic resistance genes ${ }^{12}$, presenting a significant global challenge.

Both SasG and accumulation-associated protein contain a central region with a variable (strain dependent) number of 128 amino acid repeats. The proteins are covalently attached to the cell wall at their carboxy terminus and are visible, using electron microscopy, as thin, highly extended fibrils on the cell surface (53-160 nm; strain dependent $)^{7,13}$. Many bacterial surface fibrils, such as pili, are multi-chain assemblies ${ }^{1,4,14,15}$, which can have inter- and/or intramolecular covalent cross-links to maintain strong, highly extended structures ${ }^{5,16,17}$. Monomeric proteins that are formed from $\alpha$-helical bundles can provide length ${ }^{18}$ but are intrinsically mechanically weak $^{19}$. Alternatively, monomeric proteins with tandemly arrayed $\beta$-sandwich domains (for example, titin and fibronectin) have been shown to be mechanically strong 20,21 , but these do not form highly elongated structures ${ }^{22,23}$. The tandem repeats of SasG fold into two structurally related domains: $\mathrm{E}$ (50 residues) and G5 (78 residues), formed from single-layer triple-stranded $\beta$-sheets, framing a central collagen-like triple-helical region ${ }^{24,25}$ (Fig. 1). Interestingly, the $\mathrm{E}$ domain is disordered both in isolation and when preceded by a folded G5 domain (G5-E), but folded in E-G5 and G5-E-G5 to form elongated structures ${ }^{24}$. Whether and how such tandemly repeated, relatively unstable, $\beta$-sheet domains could underpin an elongated and mechanically strong structure is unclear.

Here we use a multidisciplinary approach, combining structural, computational and biophysical methods to demonstrate that the repeat region of SasG maintains a monomeric and highly extended conformation in solution, which is resistant to significant mechanical stress. The length is achieved by obligate folding of intrinsically disordered $\mathrm{E}$ domains to form stable interfaces that couple non-adjacent G5 domains and promote long-range cooperativity. The mechanical strength of SasG arises from tandemly arrayed 'clamp' motifs within the folded G5 and E domains, formed from directly hydrogen-bonded $\beta$-strands. Our study reveals the molecular basis for the efficient formation of elongated and mechanically resistant bacterial adhesins from a single polypeptide chain.

\section{Results}

SasG is an extended monomeric molecule. Only SasG with five or more E-G5 repeats promotes biofilm formation, likely to be due to the need to project above the layer of other cell surface components ${ }^{7}$. To generate a model for the tandemly arrayed repeats, we first determined the structure of $\mathrm{G} 5^{2}-\mathrm{E}-\mathrm{G} 5^{3}$ (Supplementary Fig. 1a-h, Supplementary Table 1 and Supplementary Discussion), which has the highest sequence identity to other repeats. A model of contiguous repeats comprising all domains from $\mathrm{G}^{1}$ to $\mathrm{G}^{7}$ (generated by iterative superposition) had a length of $71 \mathrm{~nm}$ (Supplementary Fig. 1i). To assess the validity of this model experimentally, we produced constructs starting from $\mathrm{G} 5^{1}-\mathrm{E}-\mathrm{G} 5^{2}$ with E-G5 increments up to $\mathrm{G}^{1}-\mathrm{G} 5^{7}$ (Fig. 2a); all were monomeric and monodisperse (Supplementary Fig. 2a and Supplementary Table 2).

a

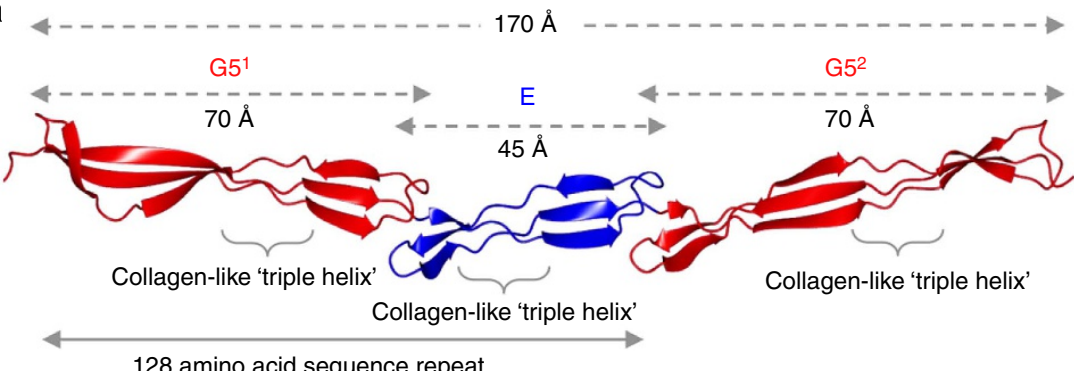

b

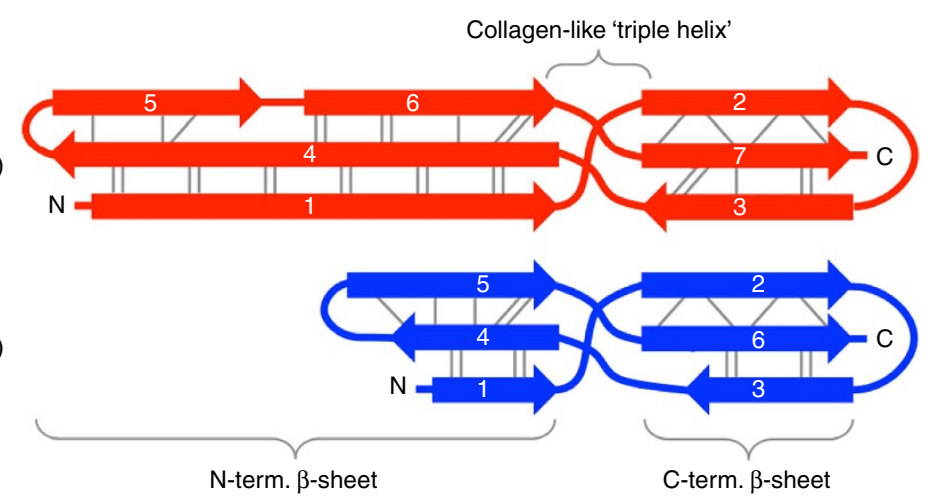

Figure 1 | Overview of the SasG system. (a) Crystal structure of G51-E-G52 (PDB accession: 3TIQ) illustrating the head-to-tail arrangement of $\mathrm{G} 5$ (red) and $\mathrm{E}$ (blue) domains in SasG. The lengths of $\mathrm{G} 5^{1}-\mathrm{E}-\mathrm{G} 5^{2}$ and individual domains, determined from the crystal structure, are shown. The 128 amino acid sequence repeat, covering a G5 and an E domain, is also indicated. (b) Schematic representation of the domain topology for G5 and E. The domains share the same fold ( $\beta$-triple helix- $\beta$ ), defined by two single-layer, triple-stranded $\beta$-sheets connected via a central collagen-like triple-helical region (also indicated in $\mathbf{a}$ ). 
a
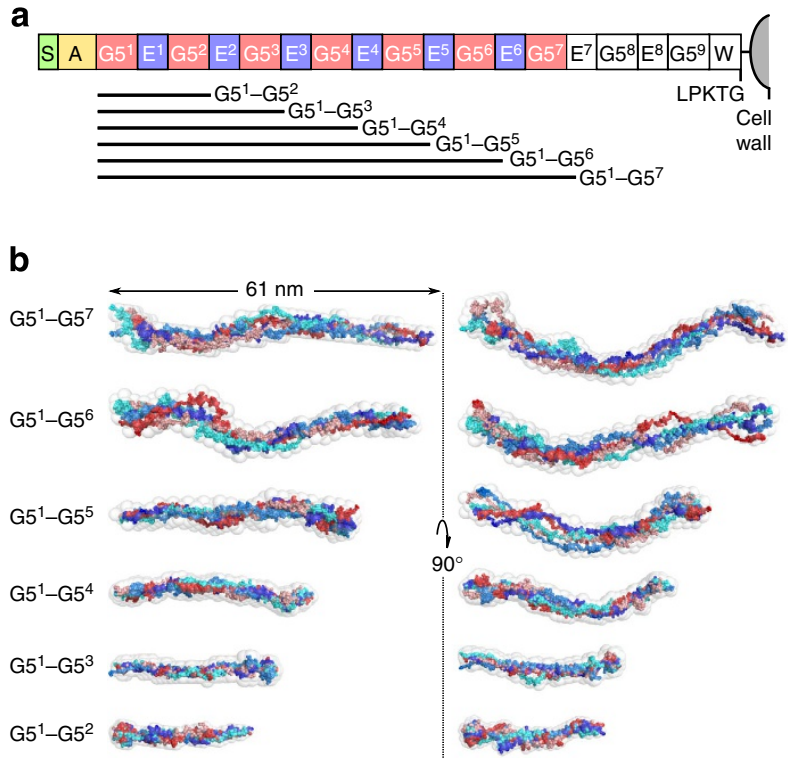

C
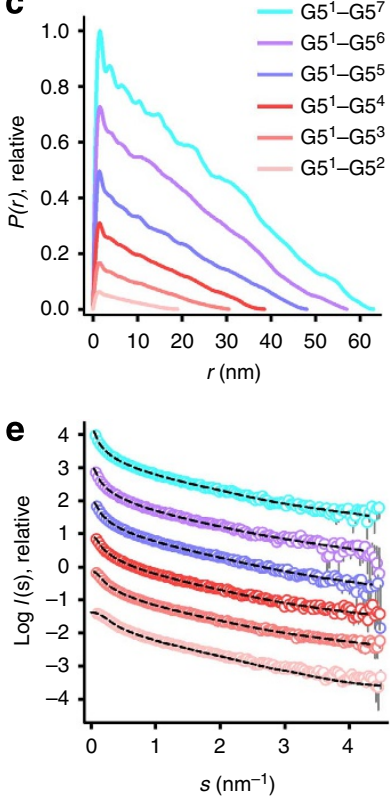

d

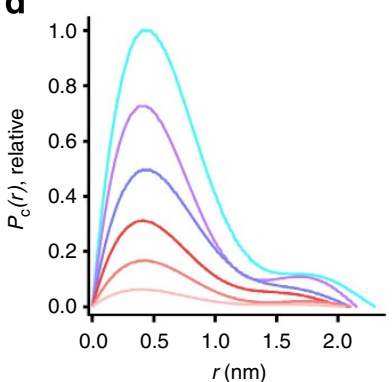

$\mathbf{f}$

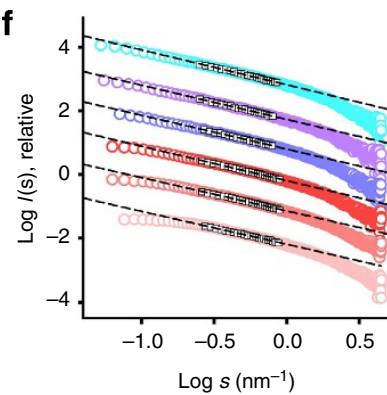

Figure 2 I SAXS analysis of SasG particle shape and size. (a) Schematic of SasG in S. aureus strain NCTC 8325-4; signal sequence (S; cleaved), adhesion domain (A), E-G5 repeats, C-terminal wall (W) region and LPKTG signal for cell wall attachment; expression constructs are illustrated below. (b-f) SAXS studies of $\mathrm{G} 5^{1}-\mathrm{G} 5^{2}, \mathrm{G} 5^{1}-\mathrm{G} 5^{3}, \mathrm{G} 5^{1}-\mathrm{G} 5^{4}, \mathrm{G} 5^{1}-\mathrm{G} 5^{5}, \mathrm{G} 5^{1}-\mathrm{G}^{6}$ and $\mathrm{G} 5^{1}-\mathrm{G} 5^{7}$ (colour legend defined in c): (b) five ab initio bead models and their filtered average (grey); (c) distance distribution functions $P(r)$ and (d) cross-sectional distance distribution functions $P_{c}(r)$ (for presentation purposes, $P(r)$ and $P_{c}(r)$ have been scaled relative to construct length); (e) SAXS profiles (offset on log scale) and calculated scattering fits (black dashed lines) for: the G5 $5^{1}-\mathrm{G} 5^{2} \mathrm{X}$-ray crystal structure and a representative Gasbor ab initio model of all other constructs (see Supplementary Table 2 for $\chi^{2}$-values). (f) Porod exponents (Log I(s) versus Log s offset on log scale; linear regression analysis (black dashed lines)) fitted to the mid-s data range (white squares with black outline).

We determined their shape in solution using small-angle X-ray scattering (SAXS) (Fig. 2b-f, Supplementary Fig. 2b-g and Supplementary Discussion). The maximum particle dimension, $D_{\max }$ of $\mathrm{G} 5^{1}-\mathrm{E}-\mathrm{G} 5^{2}$ matched the crystal structure (19 nm; Fig. $2 \mathrm{c}$ ) and the calculated scattering matched the experimental SAXS data $\left(\chi^{2}=1.12\right.$; Fig. $2 \mathrm{e}$ and Supplementary Fig. $\left.2 \mathrm{f}\right)$. The $D_{\max }$ increased incrementally with stepwise addition of E-G5 units (Fig. 2b,c). The $D_{\max }$ of $63 \mathrm{~nm}$ for $\mathrm{G} 5^{1}-\mathrm{G} 5^{7}$ is only $8 \mathrm{~nm}(\sim 11 \%)$ shorter than our (maximally extended) crystal structure-based model (Supplementary Fig. 1i). At the same time, the maximum particle cross-section (Fig. 2d and Supplementary Table 2) remains nearly unchanged and displays only a minor increase from $2.0 \mathrm{~nm}$ for $\mathrm{G} 5^{1}-\mathrm{G} 5^{2}$ to $2.3 \mathrm{~nm}$ for $\mathrm{G} 5^{1}-\mathrm{G} 5^{7}$. SAXS ab initio models (Fig. 2b) suggest that although highly extended on average, the particles may slightly coil or bend, which explains the observed increase in the effective cross-section.

To further corroborate the SAXS results, we adapted a high-resolution single-molecule imaging technique (SHRImP ${ }^{26}$; Fig. $3 \mathrm{a}$ and Supplementary Discussion). $\mathrm{G} 5^{1}-\mathrm{G} 5^{7}$, labelled with fluorophores at both ends, was visualized using total internal reflection fluorescence microscopy (TIRFM) and exhibited end-to-end distances consistent with the SAXS analysis (mean \pm s.e. $=59 \pm 5 \mathrm{~nm}$, Fig. $3 \mathrm{~b}$ and Supplementary Fig. 3a,b). As this is the first reported application of SHRImP to the measurement of an end-to-end distance in an elongated protein, a control experiment using DNA of similar predicted length was performed (Fig. 3b inset and Supplementary Fig. 3a,b inset). All-atom molecular dynamics (MD) simulations of $\mathrm{G}^{1}$-E-G5 ${ }^{2}$ show that the individual G5 and $\mathrm{E}$ domains are relatively rigid and do not bend (Fig. 3c and Supplementary Fig. 4a). Analysis of the trajectories suggests that the collagen-like triple helix region provides rigidity within the domains (Supplementary Fig. 4b). Flexing of the molecule occurs almost exclusively at the interfaces between domains, which nonetheless maintain an overall linear profile (Fig. 3c and Supplementary Fig. 4), explaining the small difference between the rigid modelling from the crystal structure (Supplementary Fig. 1i) and the solution SAXS-based model (Fig. 2b). Thus, SasG is monomeric and extended in solution on length scales consistent with the extended fibrils observed on the bacterial cell surface.

SasG behaves as series of overlapping cooperative units. To determine the molecular mechanism whereby SasG maintains an extended conformation, we investigated the stability and folding kinetics of $\mathrm{G}^{2}$ in isolation and in tandem with $\mathrm{E}\left(\mathrm{E}-\mathrm{G} 5^{2}\right)$. The unfolding was monitored by both intrinsic tyrosine fluorescence and specific FRET (Förster resonance energy transfer) measurements (Fig. 4). Irrespective of the method used, equilibrium unfolding for both $\mathrm{G}^{2}$ and $\mathrm{E}-\mathrm{G} 5^{2}$ was reversible and characterized by a single transition, indicating two-state, all-or-none unfolding for both constructs (Fig. 4). We did not observe any separate folding or unfolding events when specific FRET probes were used to monitor the folding of only $\mathrm{E}$ or $\mathrm{G} 5^{2}$ in the context of E-G5 $5^{2}$ (Fig. 4 and Supplementary Fig. 5). E-G5 ${ }^{2}$ is more stable than $\mathrm{G}^{2}$ alone, by $\sim 3.5 \mathrm{kcal} \mathrm{mol}^{-1}$ (Table 1). Although E remains unfolded $^{24}$ in $G 5^{1}-E$, once folded cooperatively with $\mathrm{G} 5^{2}, \mathrm{E}$ interacts with and stabilizes the $\mathrm{G} 5^{\mathrm{I}}$ domain such that $\mathrm{G} 5^{1}-\mathrm{E}-\mathrm{G} 5^{2}$ unfolds at even higher concentrations of denaturant and again in an apparently cooperative manner (Fig. $4 \mathrm{~b}$ and Table 1). Hence, each G5 repeat is stabilized by the folding of the following G5, even though they are not in direct contact. The instability of $\mathrm{E}$ is required for the long-range cooperativity between G5 domains; this cooperativity would not exist if the $\mathrm{E}$ domains folded independently. The entire repeat region can be considered as a series of overlapping G5-E-G5 cooperative units (Fig. 2a) and thus will form a single cooperative unit. 
a
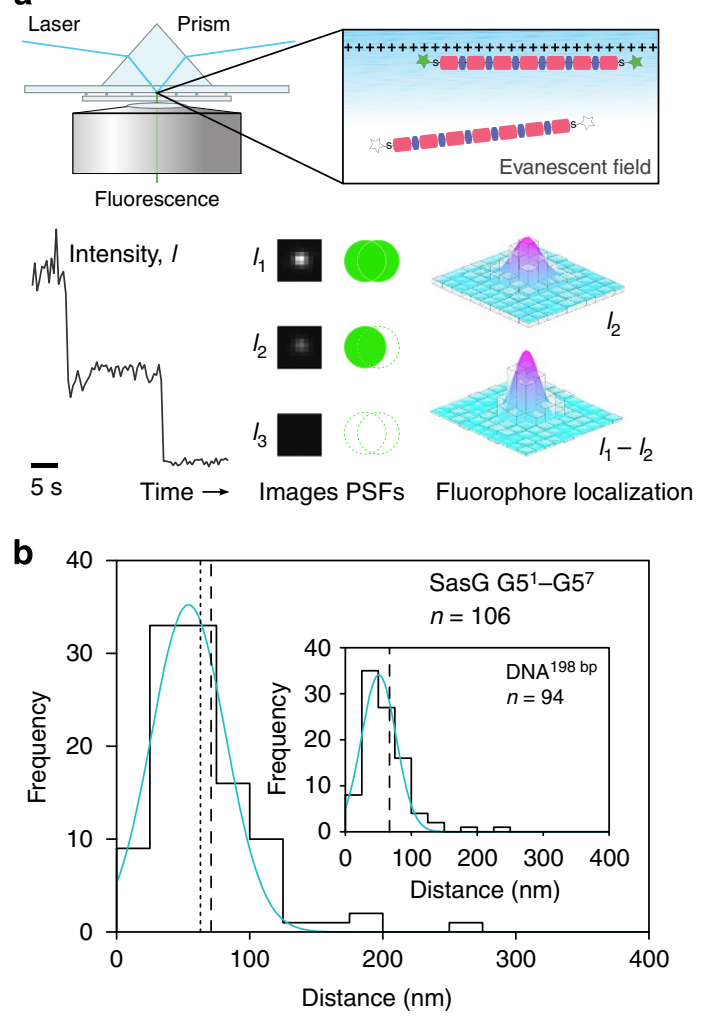

C

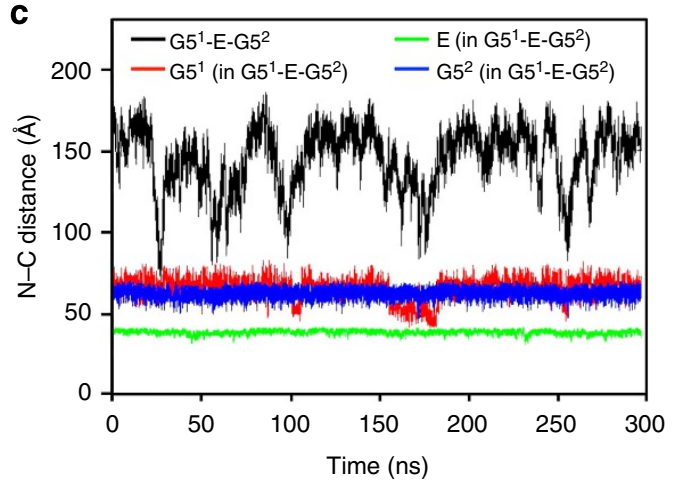

Figure 3 | Conformational flexibility of SasG. (a) SHRImP-TIRFM experimental method: Fluorophores were attached to the $\mathrm{N}$ - and $\mathrm{C}$-termini of $\mathrm{G} 5^{1}-\mathrm{G} 5^{7}$ via engineered cysteine residues. Fluorescently labelled protein was immobilized on a quartz slide surface using poly-D-lysine and visualized by prism-coupled TIRFM. By stepwise fluorophore photobleaching, individual point spread functions (PSFs) were analysed and interfluorophore distances calculated. (b) Interfluorophore distances for Alexa Fluor 488-labelled $\mathrm{G} 5^{1}-\mathrm{G} 5^{7}$ and 198 bp DNA (inset) on a poly-D-lysine $\left(100 \mu \mathrm{g} \mathrm{ml}^{-1}\right)$-treated quartz surface. Solid lines indicate Gaussian fits to the histograms (mean $=54$ and $51 \mathrm{~nm}$, respectively). Dashed lines indicate end-to-end distances based on crystallographic data for $\mathrm{G} 5^{1}-\mathrm{G} 5^{7}$ and B-form DNA (71 nm (Supplementary Fig. 1i) and $67 \mathrm{~nm}$, respectively); the dotted line indicates the SAXS determined $D_{\text {max }}$ (c) All-atom MD simulations of $\mathrm{G} 5^{1}-\mathrm{E}-\mathrm{G} 5^{2}$. The $\mathrm{N}$-to-C distance as a function of time is plotted for $\mathrm{G} 5^{1}-\mathrm{E}-\mathrm{G} 5^{2}$ (black) and individual domains within the protein ( $G 5^{1}$-red, E-green and $\mathrm{G} 5^{2}$-blue). G51-E-G5 $5^{2}$ most frequently adopts an extended conformation (with the length of $\sim 170 \AA$, as observed in the crystal structure), but rare bent conformations (Supplementary Fig. 4b) are also sampled at room temperature ( $\mathrm{N}$-to- $\mathrm{C}$ distance fluctuates between 75 and $180 \AA$ ). As the individual domains maintain their fully extended crystallographic conformations throughout the simulation, the observed flexibility of $\mathrm{G} 5^{1}-\mathrm{E}-\mathrm{G} 5^{2}$ appears due to bending at the G5-E and E-G5 interfaces (Supplementary Fig. 4).
Long-range cooperativity is mediated by intrinsic disorder. In all- $\beta$ tandem repeat proteins such as titin, with immunoglobulinlike domains, the individual domains are significantly more stable than the domains in SasG, but the domains do not fold cooperatively $^{27}$ and the proteins are not fully elongated in solution $^{22,28}$. The cooperativity in SasG is mediated by the intrinsic instability of the $\mathrm{E}$ repeats and by the relative stability of the interfaces. As explained in more detail in the Supplementary Discussion, we can estimate minimal stabilities conferred by the interfaces. The $\mathrm{G} 5^{1}-\mathrm{E}$ and $\mathrm{E}-\mathrm{G} 5^{2}$ interfaces must confer at least 1.5 and $6 \mathrm{kcal} \mathrm{mol}^{-1}$, respectively, compared with the stabilities of the individual domains $\mathrm{G} 5^{1}, \mathrm{E}$ and $\mathrm{G} 5^{2}(-3.2, \geq+2.5$ and $-2.8 \mathrm{kcal} \mathrm{mol}^{-1}$, respectively). Herein lies the explanation for the remarkable elongation of the SasG molecule. In most tandem domain protein systems, the 'weak link' is the inter-domain interface. In SasG, the interfaces provide more stability than the domains themselves and are maintained even in the most flexed structures in the MD simulations (Supplementary Fig. 4b). It is these interfaces, formed on the folding of $\mathrm{E}$, that mediate the long-range cooperativity.

The role of intrinsic disorder in promoting folding cooperativity $^{29}$ and allosteric coupling ${ }^{30,31}$ has been reported for other systems. In multi-domain proteins, where all domains are folded, cooperativity is short range and limited strictly to neighbouring domains; as has been clearly demonstrated for spectrin domains, domain $i$ will not be affected by domain $i+2$ if domain $i+1$ is stable and folded ${ }^{32}$. At the other extreme, repeat proteins, such as proteins with helical ankyrin repeats, behave cooperatively, because the individual units are highly unstable and the linking interfaces are strong ${ }^{29}$. The SasG system is an intermediate case: the regions of disorder ( $\mathrm{E}$ domains) are interspersed with stably folded G5 domains, but the high stability of the G5-E and E-G5 interfaces (relative to inherent instability of E) induces cooperativity between non-adjacent G5 domains. Thus, when $G 5^{2}$ folds, this induces the folding of $\mathrm{E}$ and facilitates formation of the $\mathrm{G} 5^{1}-\mathrm{E}$ interface, which imparts stability to $\mathrm{G} 5^{1}$.

SasG has remarkable mechanical strength. SasG is anchored to the cell wall at the C-terminus and to other cells via its N-terminus ${ }^{9}$; thus, SasG molecules are likely to experience longitudinal mechanical stress in vivo. We used atomic force microscopy (AFM) to measure the mechanical strength of SasG G5 ${ }^{1}-G 5^{7}$ (Fig. 5a). Approach-retract cycles were performed at various retraction velocities $(200,800,1,500,3,000$ and $\left.5,000 \mathrm{~nm} \mathrm{~s}^{-1}\right)$, recording the force as a function of extension (Fig. 5a,b, Supplementary Fig. 6 and Table 2). Contrary to chemical denaturation, under force, SasG domains unfold independently of each other. Irrespective of the pulling speed, two types of unfolding peaks were observed: lower- and higherforce peaks (Supplementary Fig. 6). The lower-force unfolding peaks are associated with a contour length gain $\left(\Delta L_{\mathrm{c}}\right)$ of $\sim 150 \AA$ (ranges from 145 to $154 \AA$ for different retraction rates; Supplementary Fig. 6 and Table 2) and, as the difference in length between folded and unfolded $\mathrm{E}$ is $\sim 143 \AA$, these events correspond to unfolding of $\mathrm{E}$ domains. The difference in length between folded and fully extended G5 is $\sim 213 \AA$; hence, the higher-force peaks associated with $\Delta L_{\mathrm{c}}$ of $\sim 220 \AA$ (ranges from 216 to $227 \AA$ for different retraction rates; Supplementary Fig. 6 and Table 2) represent unfolding of G5 domains. SasG domains show remarkable mechanical strength (Fig. 5b and Table 2). The weaker E domain, unstable in isolation, unfolds at forces of $250 \mathrm{pN}$ (at $800 \mathrm{nms}^{-1}$ retraction rate), which is higher than needed to unfold the 'strength-paradigm' 27th immunoglobulin domain from titin (I27; $\sim 180 \mathrm{pN})^{33}$, as well as other 'strong' proteins $^{34}$. The mechanical resistance of the G5 domain $(420 \mathrm{pN}$ 

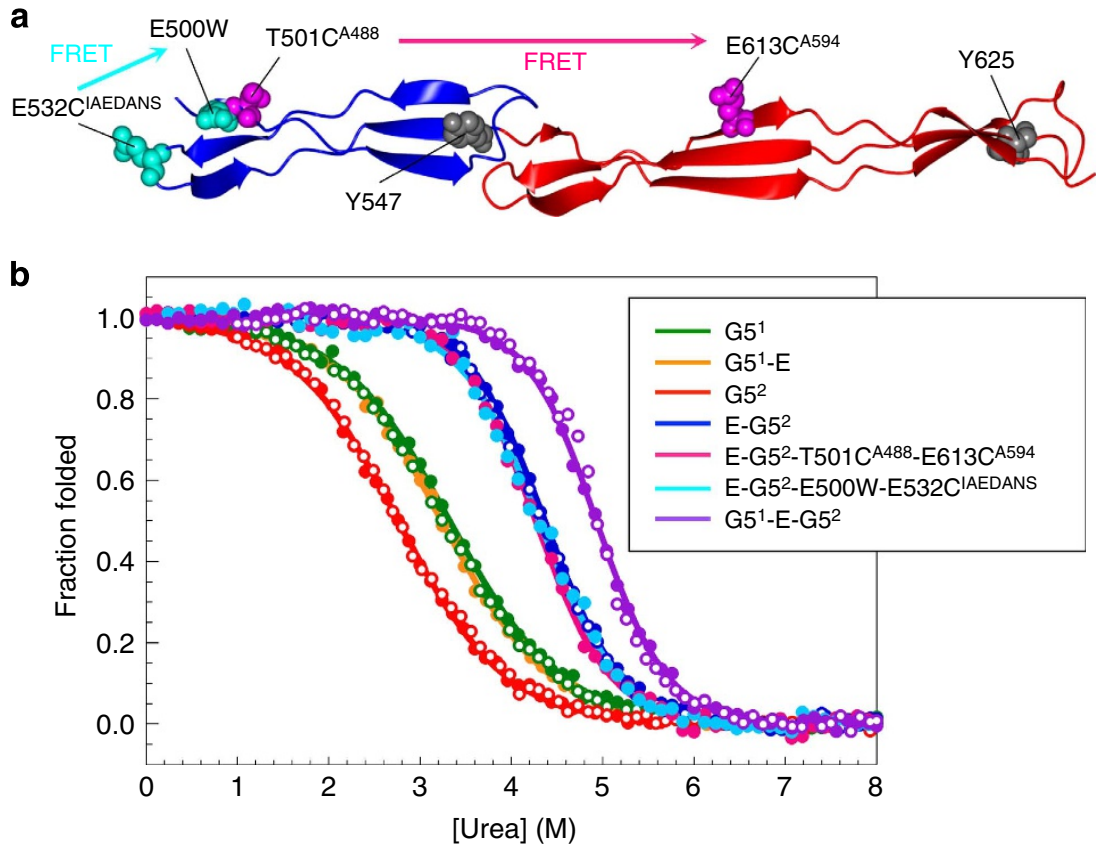

Figure 4 | Equilibrium denaturation curves for SasG domains. (a) Structure of the two-domain fragment of SasG-E-G52. E and G5 ${ }^{2}$ domains are shown in blue and red, respectively. The location of tyrosines and residues used to engineer the FRET pairs are indicated and colour-coded. E and G5 domains each contain a single tyrosine residue (grey) located in the last strand of the C-terminal $\beta$-sheet. FRET pair T501C ${ }^{A 488}$-E613C ${ }^{\text {A594 }}$ (magenta) results in FRET when both $\mathrm{E}$ and $\mathrm{G} 5^{2}$ domains are folded and was used to monitor (un)folding of E-G52. FRET pair E500W-E532CIAEDANS (cyan) results in FRET when the $\mathrm{E}$ domain is folded and was used to monitor (un)folding of $E$ in the context of E-G5². (b) Equilibrium unfolding (closed circles) and refolding (open circles) data for wild-type G5 (green), G51-E (orange), G5² (red), E-G5² (blue) and G51-E-G52 (purple), as well as E-G5²-T501C ${ }^{\mathrm{A} 488}$-E613C ${ }^{\mathrm{A} 594}$ (magenta) and E-G52-E500W-E532CIAEDANS (cyan). Data for the wild-type proteins were collected by monitoring the change in intrinsic tyrosine fluorescence, whereas the FRET signal was measured as the change in acceptor fluorescence (Alexa Fluor 594 and 1,5-IAEDANS). All data were fit to a two-state model of unfolding (see Table 1 for thermodynamic parameters).

Table 1 | Apparent equilibrium parameters for SasG domains.

G5 ${ }^{1}$-WT G5 ${ }^{1}$-E-WT G5 $^{2}$-WT E-G5 ${ }^{2}$-WT E-G5 ${ }^{2}$-T501C A488-E613CA594 E-G5 ${ }^{2}$-E500W-E532C'AEDANS

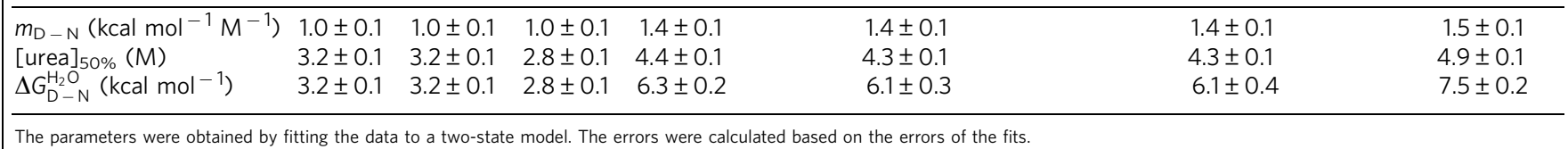

at $800 \mathrm{nms}^{-1}$ pulling speed) falls into the upper limit of mechano-stability for any protein domain stabilized solely by non-covalent interactions ${ }^{34,35}$. Mechanical unfolding of SasG domains was also predicted by MD simulations revealing that the strength originates from tandemly arrayed 'mechanical clamps ${ }^{34}$ (Fig. 5c and Supplementary Fig. 7). Mechanical clamps are structural elements that determine the protein's primary resistance to tensile force; for example, the mechanical clamps of globular $\beta$-sandwich domains, such as I27, are formed by directly hydrogen-bonded $\mathrm{N}$ - and C-terminal $\beta$-strands. In the case of SasG, E and G5 domains contain an N-terminal $\beta$-sheet clamp, formed by two anti-parallel $\beta$-strands, and a C-terminal $\beta$-sheet clamp, composed of two parallel $\beta$-strands. Both $\mathrm{N}$ - and C-terminal clamps involve long stretches of hydrogen bonds and associated side-chain packing interactions along the $\beta$-strands (Fig. 5c and Supplementary Fig. 7). G5 domains have significantly longer $\mathrm{N}$-terminal clamps than $\mathrm{E}$ domains, explaining the higher mechanical resistance of $\mathrm{G} 5$ relative to $\mathrm{E}$.

Under mechanical force, the protein is no longer behaving as a cooperative unit. E and G5 domains unfold independently; the $\mathrm{E}$ domains act as force 'buffers' relieving mechanical stress without complete unfolding of the SasG molecule. As the E domains fold rapidly when the G5 domains are folded, this allows for rapid recovery once stress is released. We speculate that SasG can oscillate between a 'flexible' state under force, with uncoupled G5 domains and E unfolded, and a 'stiff state in the absence of force with all domains folded.

\section{Discussion}

Nature can form elongated single-chain proteins or strong singlechain proteins. Here we have discovered how nature can form, from apparently insubstantial building blocks, a monomeric structure that is both long and strong. The length is maintained by using intrinsic disorder to form highly cooperative and stable interfaces that mediate communication between non-adjacent, stiff domains. Strength results from the optimal use of small domains that nonetheless contain long, aligned $\beta$-strands. Our findings provide a paradigm for efficient formation of a strong, highly elongated protein structure from a single polypeptide chain. Such protein rods of tunable length and requiring no additional covalent stabilization have significant potential for incorporation into novel biomaterials. 

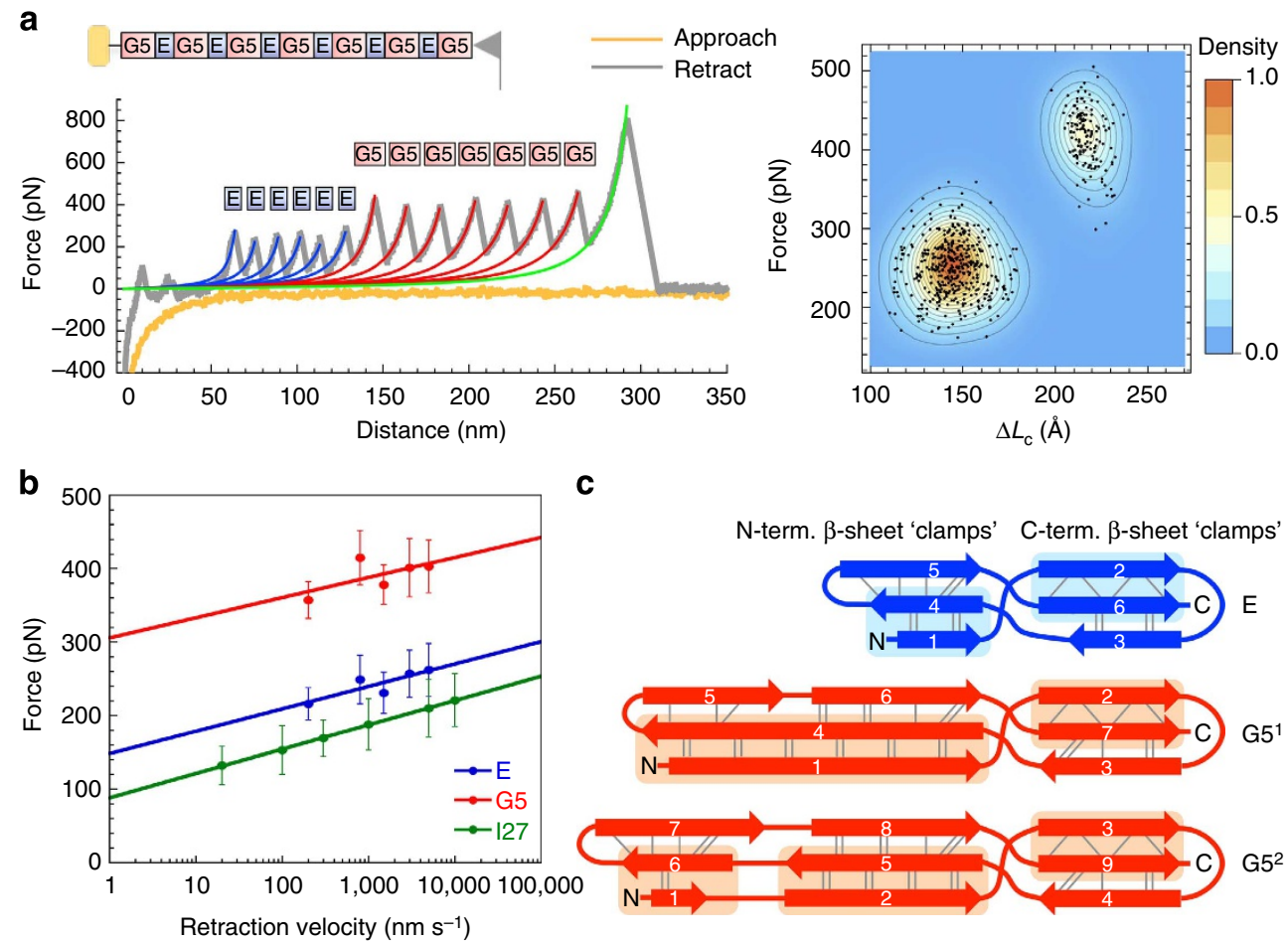

C

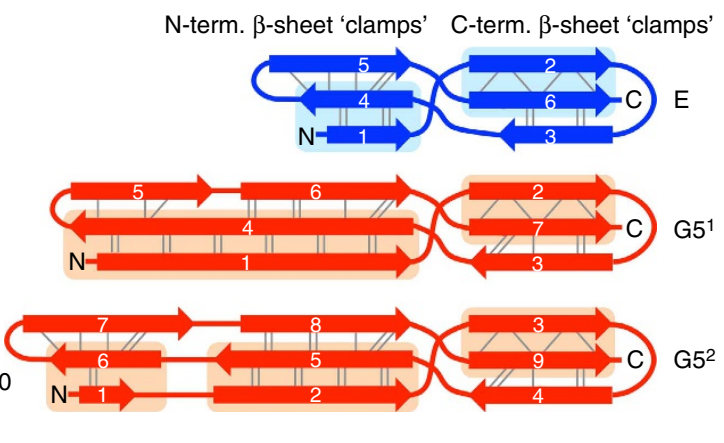

Figure 5 | Mechanical resistance of SasG domains probed by AFM. (a) A sample AFM force-extension profile for a SasG construct containing seven G5 and six E domains ( $\mathrm{G}^{1}-\mathrm{G}^{7}$; grey trace). Schematic of the experimental setup and the correlating scatter plot superposed with a smooth density histogram are also shown. The yellow trace represents the AFM cantilever tip approaching the surface. The six lower-force unfolding peaks (around $250 \mathrm{pN}$ at a retraction rate of $800 \mathrm{~nm} \mathrm{~s}^{-1}$; labelled and indicated in blue) are associated with a contour length change $\left(\Delta L_{c}\right)$ of $145 \AA$. The difference in length between a folded and unfolded $E$ is $\sim 143 \AA$ and these events thus correspond to unfolding of $E$ domains. The seven higher-force peaks (around $420 \mathrm{pN}$ at a retraction rate of $800 \mathrm{~nm} \mathrm{~s}^{-1}$; labeled and indicated in red) relate to a $\Delta L_{c}$ of $216 \AA$, and hence represent unfolding of $\mathrm{G} 5$ domains (the difference in length between a folded and unfolded G5 is $\sim 213 \AA$ ). The last force peak (indicated in green) represents the detachment of the protein from the tip or the surface. (b) Plot of mode unfolding forces (three independent experiments were performed for each pulling speed; see Supplementary Fig. 6 and Table 2 for details) against retraction velocity for SasG domains (E shown in blue and G5 in red) and I27 (shown in green; data taken from Best et al. ${ }^{70}$ ). Error bars represent s.d. E, G5 and 127 show a similar dependence of unfolding force on pulling speed, but SasG domains are mechanically more stable than 127 . (c) Topology diagrams of SasG domains $\left(\mathrm{E}, \mathrm{G} 5^{1}\right.$ and $\mathrm{G}^{2}$ ) with 'mechanical clamps' indicated as shaded boxes. Hydrogen bonds are shown as dotted lines. As revealed by MD simulations (Supplementary Fig. 7), the remarkable mechanical strength of SasG domains originates from tandemly arrayed mechanical clamps involving long stretches of hydrogen bonds and associated side-chain packing interactions along the $\beta$-strands.

Table 2 | AFM parameters for SasG domains.

\begin{tabular}{|c|c|c|c|c|c|c|}
\hline \multirow{2}{*}{$\begin{array}{l}\text { Retraction } \\
\text { rate }\left(\mathrm{nm} \mathrm{s}^{-1}\right)\end{array}$} & \multicolumn{2}{|c|}{$n$} & \multicolumn{2}{|c|}{ Force $(\mathrm{pN})^{\star}$} & \multicolumn{2}{|c|}{$\left.\Delta L_{c}(\AA)\right)^{\star}$} \\
\hline & E & G5 & E & G5 & E & G5 \\
\hline 200 & 126 & 52 & $212 \pm 25$ & $351 \pm 34$ & $149 \pm 15$ & $219 \pm 9$ \\
\hline 800 & 409 & 146 & $250 \pm 35$ & $421 \pm 36$ & $145 \pm 12$ & $216 \pm 6$ \\
\hline 1,500 & 597 & 229 & $229 \pm 27$ & $379 \pm 28$ & $154 \pm 10$ & $224 \pm 8$ \\
\hline 3,000 & 258 & 149 & $254 \pm 35$ & $397 \pm 53$ & $152 \pm 12$ & $224 \pm 13$ \\
\hline 5,000 & 547 & 263 & $265 \pm 37$ & $408 \pm 35$ & $153 \pm 13$ & $227 \pm 9$ \\
\hline
\end{tabular}

AFM, atomic force microscopy.

Note that three independent experiments were performed at each pulling speed.

*Values (mode \pm s.d.) were obtained from Gaussian fits to the histograms (see Supplementary Fig. 6).

\section{Methods}

Chemicals. All chemicals were purchased from Sigma-Aldrich, unless otherwise stated.

Protein production and characterization. Purification of short SasG repeats $\left(\mathrm{G} 5^{1}-\mathrm{G} 5^{2}\right.$; residue range 420-629) was described previously ${ }^{24}$. A construct of $\mathrm{G}^{2}-\mathrm{G}^{3}$ (residue range 545-757) was expressed and purified similarly. The coding sequences of $\mathrm{G}^{1}-\mathrm{G} 5^{3}$ (residue range $\left.419-757\right), \mathrm{G}^{1}-\mathrm{G} 5^{4}$ (419-885), G5 ${ }^{1}-\mathrm{G}^{5}$ (419-1,013), G5 $5^{1}-\mathrm{G}^{6}{ }^{2}(419-1,141)$ and $\mathrm{G} 5^{1}-\mathrm{G} 5^{7}(419-1,269)$ were synthesized by Genewiz and fused to an N-terminal hexahistidine-3C protease-cleavable tag and a non-cleavable C-terminal Strep-tag II (WSHPQFEK) in a modified pET28 vector,
pET-YSBLIC ( $\left.\mathrm{His}_{6}-3 \mathrm{C}-\mathrm{G} 5^{1}-\mathrm{G} 5^{\mathrm{x}}-\mathrm{Strep}\right)$. A second $\mathrm{G} 5^{1}-\mathrm{G} 5^{7}$ construct incorporated two cysteine residues at the C-terminus of the Strep affinity tag for AFM force unfolding studies generating $\mathrm{His}_{6}-3 \mathrm{C}-\mathrm{G} 5^{1}-\mathrm{G} 5^{7}-\mathrm{Strep}-\mathrm{CysCys}$ using primer pair:

5' -TCCAGGGACCAGCAATGGCACCTAAGACCATCACC-3'

$5^{\prime}$-TGAGGAGAAGGCGCGTTAGCAGCATTTTTCAAATTGAGGAT GAGACCAGGTCTCCGGACCATACTC-3'

A third $\mathrm{G} 5^{1}-\mathrm{G}^{7}$ construct was engineered into a XhoI/NdeI-digested pET26b $(+)$ vector (Novagen), to generate a non-cleavable C-terminal His tag; cysteine residues replaced E418 and T1269 for SHRImP-TIRFM studies (Cys-G5 $5^{1}-\mathrm{G}^{7}-\mathrm{Cys}^{-} \mathrm{His}_{6}$ ) with primers:

\section{$5^{\prime}$-AAGAAGGAGATATACATATGGGTGGCTGCGCACCTAAGACCAT} CAC- $3^{\prime}$

$5^{\prime}$-GGTGGTGGTGCTCGAGGCCGCTGCTGCCGCACTCCGGACCATACT CGG-3'

Liquid cultures of LB supplemented with $50 \mu \mathrm{g} \mathrm{ml}^{-1}$ kanamycin were inoculated with transformed Escherichia coli BL21(DE3) cells (Novagen) and grown at $37^{\circ} \mathrm{C}$ to $\mathrm{OD}_{600} 0.5-0.6$; expression was induced with addition of $1 \mathrm{mM}$ isopropyl- $\beta$-D-thiogalactopyranoside, followed by incubation at $20^{\circ} \mathrm{C}$ for $20 \mathrm{~h}$. Cells were resuspended in $500 \mathrm{mM} \mathrm{NaCl}, 20 \mathrm{mM}$ imidazole, $20 \mathrm{mM}$ Tris $\mathrm{HCl}$, pH 7.5, supplemented with EDTA-free protease inhibitor cocktail (Roche) and lysed by sonication. Soluble extract was purified by nickel affinity chromatography. Constructs with $3 \mathrm{C}$ protease sites and Strep tags were digested with HRV-3C protease and purified by Strep-Trap affinity chromatography (GE Healthcare). Eluted protein was separated by size-exclusion chromatography (SEC) on a Superdex 200 26/60 column (GE Healthcare) in $200 \mathrm{mM} \mathrm{NaCl}, 1 \mathrm{mM}$ EDTA and $20 \mathrm{mM}$ Tris $\mathrm{HCl}, \mathrm{pH} 7.5$. $^{-} \mathrm{is}_{6}-3 \mathrm{C}-\mathrm{G}^{1}{ }^{1}-\mathrm{G}^{7}$-Strep-CysCys and Cys-G5 ${ }^{1}-\mathrm{G} 5^{7}$-Cys$\mathrm{His}_{6}$ were also purified by SEC with the addition of $2.5 \mathrm{mM}$ dithiothreitol (DTT). Molecular masses were characterized by electrospray ionization mass spectrometry SAXS samples were dialysed against SEC buffer to generate matched solvent for buffer scattering subtraction. Protein concentrations were estimated by $A_{280}$. 
SEC-multi-angle laser light scattering-quasi-elastic light scattering analysis of samples in the range $1.5-2 \mathrm{mg} \mathrm{ml}^{-1}$ was performed using a Superdex 200 10/300 GL column (GE healthcare) in line with a Dawn HELEOS-II 18-angle lightscattering detector, Optilab rEX refractive index monitor and quasi-elastic light scattering detector (Wyatt).

Crystallography. $\mathrm{G5}^{2}-\mathrm{G}^{3}$ was concentrated to $26.2 \mathrm{mg} \mathrm{ml}^{-1}$ and screened for crystallization at $18^{\circ} \mathrm{C}$. Crystals grew in 3 days in JCSG-plus (Molecular Dimensions) condition D2 (0.2 $\mathrm{M} \mathrm{MgCl}_{2}, 0.1 \mathrm{M} \mathrm{Na}$ HEPES pH 7.5, 30\% v/v PEG 400). Crystals were vitrified in liquid $\mathrm{N}_{2}$ and two data sets collected from a single crystal by offsetting the crystal by $\kappa=40^{\circ}$ using a mini-Kappa goniometer at Diamond light source beamline I04, wavelength $0.9795 \AA$ at $100 \mathrm{~K}$. Data were integrated using $\mathrm{XDS}^{36}$, merged and scaled using Aimless ${ }^{37}$, and molecular replacement performed using PhaserMR ${ }^{38}$. $\mathrm{E}^{1} \mathrm{G}^{2}$ (PDB accession: 3TIP) was separated into two search models: $\mathrm{E}^{1}$ (residue range 502-548) and $\mathrm{G}^{2}$ (residue range 549-629). The model was partially built using Buccaneer ${ }^{39}$, completed with $\operatorname{Coot}^{40}$ and refined with Refmac5 (ver. 5.8.0073) ${ }^{41}$. TLSMD server was used to define translation/libration/screw groups (residue ranges 543-588, 589-677 and $678-757)^{42}$. Aimless, PhaserMR, Buccaneer and Refmac5 were implemented through the CCP4 interface ${ }^{43}$. The final model was evaluated with MolProbity ${ }^{44}$ and the Ramachandran plot showed that all residues have favourable $\varphi / \psi$ geometry. G5 $5^{1}-\mathrm{G}^{2}$ (PDB accession: 3TIQ) superposition was performed using Gesamt ${ }^{45}$. The $G 5^{1}-G 5^{7}$ particle was modelled by superposition of $G 5^{1}-G 5^{2}$ and $\mathrm{G} 5^{2}-\mathrm{G} 5^{3}$, and iterative superposition of $\mathrm{G} 5^{2}-\mathrm{G} 5^{3}$ by secondary structure matching 46 .

Small-angle X-ray scattering. SAXS intensity data, $I(s)$ versus $s,(s=4 \pi \sin \theta / \lambda$, where $2 \theta$ is the scattering angle, $0.04-4.4 \mathrm{~nm}^{-1}$ ) were collected from protein samples and matched solvent blanks at the EMBL-P12 beamline at PETRAIII (DESY, Hamburg) employing automated data acquisition and radial averaging protocols $s^{47}$. Guinier $\left(\ln I(s)\right.$ versus $\left.s^{2}\right)$ and modified Guinier analysis for extracting cross-sectional terms $\left(\ln (I(s) s)\right.$ versus $\left.s^{2}\right)$ were performed using Primus ${ }^{48}$. Indirect inverse Fourier transformations of the data were calculated using $\mathrm{GNOM}^{49}$, to generate probable real-space atom-pair distance distributions $(P(r)$ versus $r)$ and distance distributions of cross-sections $\left(P_{c}(r)\right)$. Porod exponents were calculated from the slope of linear fits to the decay in scattering intensity of $\log I(s)$ versus $\log s$ through the mid-s regions of the profiles ${ }^{50,51}$. The molecular masses (MMs) were evaluated from the forward-scattering intensity $I(0)$ placed on an absolute scale $\left(\mathrm{cm}^{-1}\right)$ using the scattering from water ${ }^{52}$, combined with calculated values of concentration, partial specific volume and scattering-length density contrasts ${ }^{53}$ derived from amino acid sequence and atomic compositions. The MM was additionally calculated relative to the scattering calibrated using a BSA standard ${ }^{54}$ and SAXS.MoW was used to estimate the concentration-independent MM based on apparent volumes ${ }^{55}$. Ab initio shape restorations using a dummy residue algorithm Gasbor ${ }^{56}$ were performed five times against each SAXS data set, and aligned and averaged using Damaver ${ }^{57}$ to generate a consensus three-dimensional shape. The model fit of the X-ray crystal structure against the SAXS data was calculated using $\mathrm{Crysol}^{58}$. Rigid body modelling was performed using SASREF ${ }^{59}$

Production of fluorescently labelled protein. Cysteine residues were engineered into the $\mathrm{N}$ - and $\mathrm{C}$ termini of $\mathrm{G} 5^{1}-\mathrm{G}^{7}$ where quenching by nearby residues is least probable. The protein $(50 \mu \mathrm{M})$ was incubated with $20 \times$ molar excess of Alexa Fluor $488 \mathrm{C}_{5}$ maleimide (Life Technologies) in $20 \mathrm{mM}$ MOPS, $200 \mathrm{mM} \mathrm{NaCl}$, $0.1 \mathrm{mM}$ tris(2-carboxyethyl)phosphine, $\mathrm{pH} 7.0$, at $25^{\circ} \mathrm{C}$ for $2 \mathrm{~h}$. The reaction was quenched by the addition of DTT to a final concentration of $5 \mathrm{mM}$. The protein was then dialysed into storage buffer $\left(20 \mathrm{mM} \mathrm{KH}_{2} \mathrm{PO}_{4} / \mathrm{K}_{2} \mathrm{HPO}_{4}, 200 \mathrm{mM} \mathrm{NaCl}\right.$, $1 \mathrm{mM}$ DTT, pH 7.5) and purified by SEC on an S200 10/300 column (Amersham), to remove all remaining free dye before storage at $-80^{\circ} \mathrm{C}$.

Production of fluorescently labelled DNA. A 215-bp DNA fragment was PCR amplified from bacteriophage T7 DNA using fluorescently labelled primers 5'-CCCCAAGCTTCATCTZGTCAGATGAGACTACCCCTCTGAA-3' and

$5^{\prime}$-CCZCAAAGTCTGTACTTTTAGTAGGTCTTATAGTCC-3'

where ' $\mathrm{Z}$ ' indicates an internal Alexa Fluor 488-dT modification, such that the fluorophores are separated by $198 \mathrm{bp}$. An inter-fluorophore distance of $62-67 \mathrm{~nm}$ was predicted using the DNA curvature analysis tool (http://www.lfd.uci.edu/ $\sim$ gohlke/dnacurve/) and model.it ${ }^{60}$, which takes into account sequence-dependent static bending.

Sample preparation for TIRF microscopy. Poly-D-lysine-coated quartz slides were prepared by incubating the slides at $20-22{ }^{\circ} \mathrm{C}$ for $30 \mathrm{~min}$ in $20-500 \mu \mathrm{g} \mathrm{ml}^{-1}$ poly-D-lysine hydrobromide ( $30-70 \mathrm{kDa}$, Sigma), $10 \mathrm{mM}$ MOPS, $\mathrm{pH}$ 7.0. The slides were then rinsed by dipping in deionized water and dried with filtered air. Alexa Fluor 488-labelled protein and DNA samples were prepared by diluting concentrated stocks into imaging buffer $(10 \mathrm{mM}$ HEPES, $10 \mathrm{mM} \mathrm{NaCl}, 5 \mu \mathrm{M} \beta$-mercaptoethanol, $1 \mathrm{mM}$ Trolox, $\mathrm{pH}$ 7.0) with streptavidin-derivatized quantum dots emitting at $655 \mathrm{~nm}(100 \mathrm{pM}$, Quantum Dot Corporation). Five-micrometre silica beads $\left(\sim 0.1 \mathrm{mg} \mathrm{ml}^{-1}\right)$ were included in all samples, to specify the height of flow cells and to prevent coupling of excitation light into the coverslip. Flow cells were constructed by applying sample $(25 \mu \mathrm{l})$ to the slide, covering with coverslip (No. 1, $22 \mathrm{~mm} \times 64 \mathrm{~mm}$, Menzel-Gläser) and sealing two opposite short sides with nail varnish. Ten minutes were allowed for the protein to immobilize. Any unbound material was subsequently washed out with two volumes of imaging buffer and the flow cell sealed with nail varnish.

TIRF microscopy. Prism-coupled TIRFM was performed using a custom-modified inverted IM 35 microscope (Carl Zeiss AG) at $20-22^{\circ} \mathrm{C}$. Fluorophores were excited with 488 and $561 \mathrm{~nm}$ lasers (Coherent) operated at $10 \mathrm{~mW}$ and $30-50 \mathrm{~mW}$ output, respectively. A 488-nm zero-order quarter-wave plate (Edmund Optics) was installed to circularly polarize the incident laser light, thus removing any dye orientation-dependent fluorescence excitation. The quantum dots were used as an image-focusing aid (with $561 \mathrm{~nm}$ laser illumination only), thus minimizing Alexa Fluor 488 dye photobleaching before video acquisition. Fluorescence emission was captured through a Plan-Apochromat $\times 100$ /numerical aperture 1.4 oil-immersion objective (Carl Zeiss AG). A dual-view image splitter (OptoSplit II, Cairn Research) with appropriate emission dichroic (580 nm long pass, Zeiss) and bandpass filters for the Alexa Fluor 488 dye (ET525/50M, Chroma) and quantum dots (ET605/70M, Chroma) was used to split the image into two fluorescence emission channels. Video data were collected using an Evolve 512 electron-multiplying CCD (charge-coupled device) camera (Photometrics), cooled to $-70^{\circ} \mathrm{C}$ and operated through $\mu$ Manager ${ }^{61}$ with $500 \mathrm{~ms}$ exposure $(2 \mathrm{fps})$. Pixel size was equivalent to $157 \mathrm{~nm}$ in the magnified image as determined using a USAF calibration target (Edmund Optics).

Detection and localization of single fluorophores. Fluorescent spots were detected using the multi-step test (using standardized full width at half maximum and intensity threshold values) in GMimPro ${ }^{62}$. Fluorophores that photobleached in two steps were manually selected and their $x, y$ coordinates exported. Spot intensities for individual particles were then extracted in Image ${ }^{63}$ as an image stack for a $10 \times 10$ pixel $^{2}$ area. Subsequently in MATLAB (MathWorks, Cambridge, UK), the intensity profile of each particle was processed using a Chung-Kennedy filter ${ }^{64}$ and a derivative-based step detection method was implemented to identify the three intensity states of the particle: $I_{1}$, two fluorophores fluorescing; $I_{2}$, one fluorescing; $I_{3}$, none fluorescing. Mean images of the seven frames before and after the first step were used to calculate $I_{1}$ and $I_{2}$, respectively. Fluorophore locations were determined by fitting a two-dimensional Gaussian function (with integration over each pixel) to $I_{2}$ and the difference between $I_{1}$ and $I_{2}$ :

$$
\begin{aligned}
I= & A \exp \left(-\left(\left(\frac{\cos ^{2} \theta}{2 \sigma_{x}^{2}}+\frac{\sin ^{2} \theta}{2 \sigma_{y}^{2}}\right)\left(x-x_{0}\right)^{2}+\left(\frac{\sin 2 \theta}{2 \sigma_{x}^{2}}-\frac{\sin 2 \theta}{2 \sigma_{y}^{2}}\right)\left(x-x_{0}\right)\left(y-y_{0}\right)\right.\right. \\
& \left.\left.+\left(\frac{\sin ^{2} \theta}{2 \sigma_{x}^{2}}+\frac{\cos ^{2} \theta}{2 \sigma_{y}^{2}}\right)\left(y-y_{0}\right)^{2}\right)\right)+B
\end{aligned}
$$

where $A$ is amplitude with centre $\left(x_{0}, y_{0}\right), \sigma_{x}$ and $\sigma_{y}$ describe the widths, $\theta$ specifies rotation of the function about the centre and $B$ accounts for background intensity. End-to-end distances were calculated for pairs of fluorophores with eccentricity $<0.04$ and presented as histograms. A bin size of $25 \mathrm{~nm}$ was chosen to satisfy the Freedman-Diaconis rule ${ }^{65}$. A Gaussian distribution of the form

$$
y=a \exp \left(\frac{-(x-\mu)^{2}}{2 \sigma^{2}}\right)+b
$$

was fitted to each histogram.

MD simulations. Simulations were performed using a united-atom force field (CHARMM19) and implicit solvent model (FACTS). All simulations were performed at $300 \mathrm{~K}$, with Langevin dynamics using the leapfrog integrator, a timestep of $2 \mathrm{fs}$ and a friction coefficient of $3 \mathrm{ps}^{-1}$, and run using CHARMM. The CHARMM19 FACTS parameters used were: dielectric constant $=2.0$, nonpolar surface tension coefficient $=0.015 \mathrm{kcal} \mathrm{mol}^{-1} \AA^{-2}$. Within the FACTS implicit solvent, the influence of salt has been taken into account on the Debye-Hückel level $^{66}$. The friction coefficient of $3 \mathrm{ps}^{-1}$ corresponds to a viscosity about 20 times smaller than that of water, thus enhancing sampling efficiency by a corresponding factor, but it is sufficiently large to ensure that dynamics is diffusive and mechanisms observed independent on the friction coefficient ${ }^{67}$. Trajectory frames (and associated analysis parameters) were recorded every 500 steps. Simulation for $\mathrm{G} 5^{1}-\mathrm{E}-\mathrm{G} 5^{2}$ was started from the crystal structure (PDB accession: 3TIQ) and continued for $930 \mathrm{~ns}$. Forced unfolding was simulated by attaching an ideal spring to the $\mathrm{N}$ and $\mathrm{C}$ atoms of the two termini and retracting them at constant speed. Simulations were performed in conditions corresponding to monovalent salt concentration of both 0 and $200 \mathrm{mM}$ (experiments were performed in solution containing between 140 and $200 \mathrm{mM} \mathrm{NaCl}$ ). No significant differences were observed between low $(0 \mathrm{mM})$ and higher salt $(200 \mathrm{mM})$ conditions. 
FRET labelling. Tryptophan (E500W) and cysteine (T501C, E532C and E613C) residues were introduced by site-directed mutagenesis using the following primers: E500W

5'-GTTCTGTTCCAGGGGCCCTGGACGATCGCGCCGGGTC-3' 5'-GACCCGGCGCGATCGTCCAGGGCCCCTGGAACAGAAC-3' T501C

$5^{\prime}$-GTTCCAGGGGCCCGAATGTATCGCGCCGGGTCACC-3' $5^{\prime}$-GGTGACCCGGCGCGATACATTCGGGCCCCTGGAAC-3' E532C

5'-CCGGGTATCAAAAACCCGTGTACCGGTGACGTTGTTCGTCC-3' 5'-GGACGAACAACGTCACCGGTACACGGGTTTTTGATACCCGG-3' E613C

5'-CATCTCTAAAGGTGAATCTAAAGAATGTATCACCAAAGACCCGA

TCAACGAAC- $3^{\prime}$

5'-GTTCGTTGATCGGGTCTTTGGTGATACATTCTTTAGATTCACC TTTAGAGATG- $3^{\prime}$

Labelling was carried out using thiol-reactive probes, according to manufacturer's procedures. Labelling of E-G52-E500W-E532C was performed by mixing reduced protein with a 20 -fold molar excess of 5 -((( (2-iodoacetyl)amino) ethyl)amino)naphthalene-1-sulfonic acid (1,5-IAEDANS; Life Technologies; acceptor). The labelling reaction proceeded for $\sim 14 \mathrm{~h}$ at $4{ }^{\circ} \mathrm{C}$. Unreacted dye was removed by gel filtration (HiTrap Desalting column; GE Healthcare) and the degree of labelling was estimated as $\sim 100 \%$. Labelling of E-G5 ${ }^{2}$-T501C-E613C was carried out using Alexa Fluor 488 (donor) and Alexa Fluor 594 (acceptor) maleimides (Life Technologies). The dyes were added to reduced protein simultaneously in equimolar ratios and incubated at $4{ }^{\circ} \mathrm{C}$ for $\sim 14 \mathrm{~h}$. Unreacted dyes were removed by gel filtration (HiTrap Desalting column; GE Healthcare) and the hetero-doubly labelled protein (E-G5 ${ }^{2}-T_{\left.501 C^{A 488 / 594}-E 613 C^{A 488 / 594}\right) \text { was }}$ isolated on a HiTrapQ HP column (GE Healthcare).

Equilibrium studies. The free energy of unfolding of the proteins was determined by chemical denaturation using urea. Fluorescence measurements were carried out on a Perkin Elmer LS55 fluorescence spectrometer under standard conditions $\left(\mathrm{PBS}, 25^{\circ} \mathrm{C}\right)$. The samples were equilibrated for at least $2 \mathrm{~h}$ before data collection. In the intrinsic tyrosine fluorescence studies, the protein concentration was $5 \mu \mathrm{M}$, the excitation wavelength used was $276 \mathrm{~nm}$ and the emission was followed at $305 \mathrm{~nm}$. In the case of E-G5 ${ }^{2}$-E500W-E532C IAEDANS , the protein concentration was $500 \mathrm{nM}$, the excitation wavelength was $280 \mathrm{~nm}$ (tryptophan excitation) and the emission was followed at $493 \mathrm{~nm}$ (IAEDANS fluorescence). The data for E-G52-T501C ${ }^{\mathrm{A} 488}-\mathrm{E} 613 \mathrm{C}^{\mathrm{A} 594}$ were collected at a protein concentration of $50 \mathrm{nM}$, the excitation wavelength was $495 \mathrm{~nm}$ (Alexa Fluor 495 excitation) and the emission was followed at $612 \mathrm{~nm}$ (Alexa Fluor 594 fluorescence). The data were fit to a standard two-state equation.

Kinetic studies. The kinetic experiments monitoring fluorescence change were carried out using an Applied Photophysics SX.20 stopped-flow fluorimeter maintained at a temperature of $25^{\circ} \mathrm{C}$. The final protein concentration and the excitation wavelength used were the same as described for equilibrium studies. No cut-off filter was used in the experiments for wild-type proteins monitoring the change in tyrosine fluorescence. Cut-off filters ( 435 and $590 \mathrm{~nm}$ ) were used to collect the data for E-G5 ${ }^{2}$-E500W-E532C ${ }^{\mathrm{IAEDANS}}$ and E-G5 ${ }^{2}$-T501C $\mathrm{C}^{\mathrm{A} 88 / 594}$-E613C $\mathrm{C}^{\mathrm{A} 488 / 594}$, respectively. At least 20 traces were averaged for a typical measurement at a given urea concentration. Kinetic traces were analyzed using Kaleidagraph 4.1.3 (Synergy Software). All rate constants were independent of protein concentration under the experimental conditions. Chevron plots (the dependence of the logarithm of the observed rate constant on the concentration of urea) were fit either to a standard two-state model or a sequential transition state model.

Atomic force microscopy. AFM measurements were performed using a $G 5^{1}-G 5^{7}$ construct with two cysteine residues incorporated at the $\mathrm{C}$ terminus, to allow attachment to the gold-covered surfaces via gold-thiol covalent attachment. All AFM measurements were carried out in $20 \mathrm{mM}$ Tris (pH 7.5), $150 \mathrm{mM} \mathrm{NaCl}$, at $25^{\circ} \mathrm{C}$, using an Asylum Research MFP-3D microscope. Silicon nitride cantilevers with nominal spring constant of $30 \mathrm{pN} \mathrm{nm}^{-1}$ (Bruker MLCT) were used and calibrated using the thermal method ${ }^{68}$. One hundred-microlitre protein solution $\left(250 \mu \mathrm{g} \mathrm{ml}^{-1}\right.$ in AFM buffer) was adsorbed onto a gold surface and the AFM cantilever tip was used to pick it up by nonspecific adhesion, and then retracted at a constant speed $\left(200,800,1,500,3,000\right.$ and $\left.5,000 \mathrm{~nm} \mathrm{~s}^{-1}\right)$, measuring the force exerted by the protein in the process. Three independent experiments (different cantilevers and surfaces) were performed for each pulling speed. The unfolding force for all events from acceptable traces were measured and their force-extension profiles fitted to the worm-like chain model ${ }^{69}$ (with the persistence length fixed to $400 \mathrm{pm}$ ) using the IGOR Pro 6 software (WaveMetrics) to obtain $\Delta L_{\mathrm{c}}$ values. The data from triplicates were pooled and the force and $\Delta L_{\mathrm{c}}$ probability histograms were generated for each retraction rate. The modal force and $\Delta L_{\mathrm{c}}$ values were calculated from Gaussian fits to the histograms using Mathematica 10 (Wolfram Research).

\section{References}

1. Lillington, J., Geibel, S. \& Waksman, G. Biogenesis and adhesion of type 1 and P pili. Biochim. Biophys. Acta 1840, 2783-2793 (2014).

2. Schoeler, C. et al. Ultrastable cellulosome-adhesion complex tightens under load. Nat. Commun. 5, 5635 (2014).

3. Kwon, H., Squire, C. J., Young, P. G. \& Baker, E. N. Autocatalytically generated Thr-Gln ester bond cross-links stabilize the repetitive Ig-domain shaft of a bacterial cell surface adhesin. Proc. Natl Acad. Sci. USA 111, 1367-1372 (2014).

4. Hilleringmann, M. et al. Molecular architecture of Streptococcus pneumoniae TIGR4 pili. EMBO J. 28, 3921-3930 (2009).

5. Kang, H. J., Coulibaly, F., Clow, F., Proft, T. \& Baker, E. N. Stabilizing isopeptide bonds revealed in Gram-positive bacterial pilus structure. Science 318, 1625-1628 (2007)

6. Kang, H. J. \& Baker, E. N. Intramolecular isopeptide bonds: protein crosslinks built for stress? Trends Biochem. Sci. 36, 229-237 (2011).

7. Corrigan, R. M., Rigby, D., Handley, P. \& Foster, T. J. The role of Staphylococcus aureus surface protein SasG in adherence and biofilm formation. Microbiology 153, 2435-2446 (2007).

8. Rohde, H. et al. Induction of Staphylococcus epidermidis biofilm formation via proteolytic processing of the accumulation-associated protein by staphylococcal and host proteases. Mol. Microbiol. 55, 1883-1895 (2005).

9. Roche, F. M., Meehan, M. \& Foster, T. J. The Staphylococcus aureus surface protein SasG and its homologues promote bacterial adherence to human desquamated nasal epithelial cells. Microbiology 149, 2759-2767 (2003).

10. Costerton, J. W., Stewart, P. S. \& Greenberg, E. P. Bacterial biofilms: a common cause of persistent infections. Science 284, 1318-1322 (1999).

11. Hall-Stoodley, L., Costerton, J. W. \& Stoodley, P. Bacterial biofilms: from the natural environment to infectious diseases. Nat. Rev. Microbiol. 2, 95-108 (2004).

12. Ghigo, J. M. Natural conjugative plasmids induce bacterial biofilm development. Nature 412, 442-445 (2001).

13. Banner, M. A. et al. Localized tufts of fibrils on Staphylococcus epidermidis NCTC 11047 are comprised of the accumulation-associated protein. J. Bacteriol. 189, 2793-2804 (2007).

14. Ton-That, H., Marraffini, L. A. \& Schneewind, O. Sortases and pilin elements involved in pilus assembly of Corynebacterium diphtheriae. Mol. Microbiol. 53, 251-261 (2004).

15. Craig, L., Pique, M. E. \& Tainer, J. A. Type IV pilus structure and bacterial pathogenicity. Nat. Rev. Microbiol. 2, 363-378 (2004)

16. Kang, H. J., Paterson, N. G., Gaspar, A. H., Ton-That, H. \& Baker, E. N. The Corynebacterium diphtheriae shaft pilin SpaA is built of tandem Ig-like modules with stabilizing isopeptide and disulfide bonds. Proc. Natl Acad. Sci. USA 106, 16967-16971 (2009).

17. Kang, H. J. et al. A slow-forming isopeptide bond in the structure of the major pilin SpaD from Corynebacterium diphtheriae has implications for pilus assembly. Acta Crystallogr. D 70, 1190-1201 (2014).

18. Sakamoto, S. et al. Electron microscopy and computational studies of Ebh, a giant cell-wall-associated protein from Staphylococcus aureus. Biochem. Biophys. Res. Commun. 376, 261-266 (2008).

19. Rief, M., Pascual, J., Saraste, M. \& Gaub, H. E. Single molecule force spectroscopy of spectrin repeats: low unfolding forces in helix bundles. J. Mol. Biol. 286, 553-561 (1999).

20. Rief, M., Gautel, M., Oesterhelt, F., Fernandez, J. M. \& Gaub, H. E. Reversible unfolding of individual titin immunoglobulin domains by AFM. Science 276, 1109-1112 (1997).

21. Oberhauser, A. F., Badilla-Fernandez, C., Carrion-Vazquez, M. \& Fernandez, J. M. The mechanical hierarchies of fibronectin observed with single-molecule AFM. J. Mol. Biol. 319, 433-447 (2002).

22. Wang, K., Ramirez-Mitchell, R. \& Palter, D. Titin is an extraordinarily long, flexible, and slender myofibrillar protein. Proc. Natl Acad. Sci. USA 81, 3685-3689 (1984).

23. Erickson, H. P., Carrell, N. \& McDonagh, J. Fibronectin molecule visualized in electron microscopy: a long, thin, flexible strand. J. Cell Biol. 91, 673-678 (1981).

24. Gruszka, D. T. et al. Staphylococcal biofilm-forming protein has a contiguous rod-like structure. Proc. Natl Acad. Sci. USA 109, E1011-E1018 (2012).

25. Conrady, D. G., Wilson, J. J. \& Herr, A. B. Structural basis for $\mathrm{Zn}^{2+}$-dependent intercellular adhesion in staphylococcal biofilms. Proc. Natl Acad. Sci. USA 110, E202-E211 (2013).

26. Gordon, M. P., Ha, T. \& Selvin, P. R. Single-molecule high-resolution imaging with photobleaching. Proc. Natl Acad. Sci. USA 101, 6462-6465 (2004).

27. Scott, K. A., Steward, A., Fowler, S. B. \& Clarke, J. Titin: a multidomain protein that behaves as the sum of its parts. J. Mol. Biol. 315, 819-829 (2002).

28. von Castelmur, E. et al. A regular pattern of Ig super-motifs defines segmental flexibility as the elastic mechanism of the titin chain. Proc. Natl Acad. Sci. USA 105, 1186-1191 (2008)

29. Aksel, T., Majumdar, A. \& Barrick, D. The contribution of entropy, enthalpy, and hydrophobic desolvation to cooperativity in repeat-protein folding. Structure 19, 349-360 (2011). 
30. Hilser, V. J. \& Thompson, E. B. Intrinsic disorder as a mechanism to optimize allosteric coupling in proteins. Proc. Natl Acad. Sci. USA 104, 8311-8315 (2007).

31. Simon, A. J., Vallee-Belisle, A., Ricci, F. \& Plaxco, K. W. Intrinsic disorder as a generalizable strategy for the rational design of highly responsive, allosterically cooperative receptors. Proc. Natl Acad. Sci. USA 111, 15048-15053 (2014).

32. Batey, S., Nickson, A. A. \& Clarke, J. Studying the folding of multidomain proteins. HFSP J. 2, 365-377 (2008).

33. Carrion-Vazquez, M. et al. Mechanical and chemical unfolding of a single protein: a comparison. Proc. Natl Acad. Sci. USA 96, 3694-3699 (1999).

34. Hoffmann, T., Tych, K. M., Hughes, M. L., Brockwell, D. J. \& Dougan, L. Towards design principles for determining the mechanical stability of proteins. Phys. Chem. Chem. Phys. 15, 15767-15780 (2013).

35. Valbuena, A. et al. On the remarkable mechanostability of scaffoldins and the mechanical clamp motif. Proc. Natl Acad. Sci. USA 106, 13791-13796 (2009).

36. Kabsch, W. XDS. Acta Crystallogr. D 66, 125-132 (2010).

37. Evans, P. R. An introduction to data reduction: space-group determination, scaling and intensity statistics. Acta Crystallogr. D 67, 282-292 (2011).

38. McCoy, A. J. et al. Phaser crystallographic software. J. Appl. Crystallogr. 40, 658-674 (2007)

39. Cowtan, K. The Buccaneer software for automated model building. 1. Tracing protein chains. Acta Crystallogr. D 62, 1002-1011 (2006).

40. Emsley, P., Lohkamp, B., Scott, W. G. \& Cowtan, K. Features and development of Coot. Acta Crystallogr. D 66, 486-501 (2010).

41. Murshudov, G. N. et al. REFMAC5 for the refinement of macromolecular crystal structures. Acta Crystallogr. D 67, 355-367 (2011).

42. Painter, J. \& Merritt, E. A. TLSMD web server for the generation of multi-group TLS models. J. Appl. Crystallogr. 39, 109-111 (2006).

43. Bailey, S. The CCP4 suite: programs for protein crystallography. Acta Crystallogr. D 50, 760-763 (1994).

44. Lovell, S. C. et al. Structure validation by Calpha geometry: phi,psi and Cbeta deviation. Proteins 50, 437-450 (2003).

45. Krissinel, E. Enhanced fold recognition using efficient short fragment clustering. J. Mol. Biochem. 1, 76-85 (2012)

46. Krissinel, E. \& Henrick, K. Secondary-structure matching (SSM), a new tool for fast protein structure alignment in three dimensions. Acta Crystallogr. D 60, 2256-2268 (2004).

47. Franke, D., Kikhney, A. G. \& Svergun, D. I. Automated acquisition and analysis of small angle X-ray scattering data. Nucl. Instr. Meth. Phys. Res. A 689, 52-59 (2012).

48. Konarev, P. V., Volkov, V. V., Sokolova, A. V., Koch, M. H. J. \& Svergun, D. I. PRIMUS: a Windows PC-based system for small-angle scattering data analysis. J. Appl. Crystallogr. 36, 1277-1282 (2003).

49. Svergun, D. I. Determination of the regularization parameter in indirect-transform methods using perceptual criteria. J. Appl. Crystallogr. 25, 495-503 (1992).

50. Schmidt, P. W. Small-angle scattering studies of disordered, porous and fractal systems. J. Appl. Crystallogr. 24, 414-435 (1991).

51. Beaucage, G. Small-angle scattering from polymeric mass fractals of arbitrary mass-fractal dimension. J. Appl. Crystallogr. 29, 134-146 (1996).

52. Orthaber, D., Bergmann, A. \& Glatter, O. SAXS experiments on absolute scale with Kratky systems using water as a secondary standard. J. Appl. Crystallogr. 33, 218-225 (2000).

53. Whitten, A. E., Cai, S. Z. \& Trewhella, J. MULCh: modules for the analysis of small-angle neutron contrast variation data from biomolecular assemblies. J. Appl. Crystallogr. 41, 222-226 (2008).

54. Mylonas, E. \& Svergun, D. I. Accuracy of molecular mass determination of proteins in solution by small-angle X-ray scattering. J. Appl. Crystallogr. 40, S245-S249 (2007).

55. Fischer, H., Neto, M. D., Napolitano, H. B., Polikarpov, I. \& Craievich, A. F. Determination of the molecular weight of proteins in solution from a single small-angle X-ray scattering measurement on a relative scale. J. Appl. Crystallogr. 43, 101-109 (2010).

56. Svergun, D. I., Petoukhov, M. V. \& Koch, M. H. J. Determination of domain structure of proteins from X-ray solution scattering. Biophys. J. 80, 2946-2953 (2001).

57. Volkov, V. V. \& Svergun, D. I. Uniqueness of $a b$ initio shape determination in small-angle scattering. J. Appl. Crystallogr. 36, 860-864 (2003).

58. Svergun, D., Barberato, C. \& Koch, M. H. J. CRYSOL - a program to evaluate $\mathrm{X}$-ray solution scattering of biological macromolecules from atomic coordinates. J. Appl. Crystallogr. 28, 768-773 (1995).

59. Petoukhov, M. V. \& Svergun, D. I. Global rigid body modeling of macromolecular complexes against small-angle scattering data. Biophys. J. 89, 1237-1250 (2005).

60. Munteanu, M. G., Vlahovicek, K., Parthasarathy, S., Simon, I. \& Pongor, S. Rod models of DNA: sequence-dependent anisotropic elastic modelling of local bending phenomena. Trends Biochem. Sci. 23, 341-347 (1998).
61. Edelstein, A., Amodaj, N., Hoover, K., Vale, R. \& Stuurman, N. Computer control of microscopes using microManager. Curr. Protoc. Mol. Biol. 92 Chapter 14, Unit 14.20 (2010).

62. Mashanov, G. I. \& Molloy, J. E. Automatic detection of single fluorophores in live cells. Biophys. J. 92, 2199-2211 (2007).

63. Schneider, C. A., Rasband, W. S. \& Eliceiri, K. W. NIH Image to ImageJ: 25 years of image analysis. Nat. Methods 9, 671-675 (2012).

64. Chung, S. H. \& Kennedy, R. A. Forward-backward non-linear filtering technique for extracting small biological signals from noise. J. Neurosci. Methods 40, 71-86 (1991).

65. Freedman, D. \& Diaconis, P. On the histogram as a density estimator: L2 theory. Z. Wahrscheinlichkeit. 57, 453-476 (1981).

66. Srinivasan, J., Trevathan, M. W., Beroza, P. \& Case, D. A. Application of a pairwise generalized born model to proteins and nucleic acids: inclusion of salt effects. Theor. Chem. Acc. 101, 426-434 (1999).

67. Best, R. B. \& Hummer, G. Diffusive model of protein folding dynamics with Kramers turnover in rate. Phys. Rev. Lett. 96, 228104 (2006).

68. Hutter, J. L. \& Bechhoefer, J. Calibration of atomic-force microscope tips. Rev. Sci. Instrum. 64, 1868-1873 (1993).

69. Marko, J. F. \& Siggia, E. D. Stretching DNA. Macromolecules 28, 8759-8770 (1995).

70. Best, R. B. \& Clarke, J. What can atomic force microscopy tell us about protein folding? Chem. Commun. 3, 183-192 (2002).

\section{Acknowledgements}

This research was supported by Biotechnology and Biological Research Council Grants BB/J006459/1 (D.T.G. and J.C.), BB/J005029/1 (F.W. and J.R.P), BB/G019452/1 (O.E.F. and D.J.B.) and BB/G020671/1 (C.G.B. and J.R.P.). H.K.H.F. is supported by a studentship from a Wellcome Trust 4-year PhD programme (WT095024MA). C.M.J. is supported by the German Federal Ministry of Education and Research (BMBF), grant BIOSCAT (contract number 05K12YE1). J.C. is a Wellcome Trust Senior Research Fellow (WT/095195). J.R.P. holds a British Heart Foundation Senior Basic Science Fellowship (FS/12/36/29588). We acknowledge the use of EMBL SAXS beamline P12 at Petra-3 (DESY, Hamburg, Germany) and Maxim Petoukhov (EMBL) for providing a modified version of SASREF. The research leading to these results has received funding from the European Community's Seventh Framework Programme (FP7/2007-2013) under BioStruct-X (grant agreement number 283570). We thank Diamond Light Source for beamtime (proposal mx-7864) and Johan Turkenburg and Sam Hart for assistance with crystal testing and data collection.

\section{Author contributions}

D.T.G., F.W., J.R.P. and J.C. designed the investigation. F.W. produced proteins for SAXS, single-molecule fluorescence imaging and AFM, and characterized these samples. F.W., C.B. and C.M.J. collected SAXS data. F.W. and C.M.J. processed and analysed SAXS data. C.M.J. performed SAXS ab initio and rigid body modelling. H.K.H.F. and C.G.B. performed the single-molecule fluorescence imaging experiments. D.T.G. produced samples and performed folding studies. D.T.G. and O.E.F. collected AFM data, which were analysed by D.T.G., O.E.F. and D.J.B. E.P. performed MD simulations. E.P. and D.T.G. analysed MD simulations. D.T.G., F.W., J.R.P. and J.C. wrote the manuscript. All other authors discussed and commented on the manuscript.

\section{Additional information}

Accession codes: The atomic coordinates have been deposited in the Protein Data Bank under accession code number 4WVE. SAXS data and models have been deposited in the Small Angle Scattering Biological Data Bank www.sasbdb.org with codes SASDA37, SASDA47, SASDA57, SASDA67, SASDA77 and SASDA87.

Supplementary Information accompanies this paper at http://www.nature.com/ naturecommunications

Competing financial interests: The authors declare no competing financial interests.

Reprints and permission information is available online at http://npg.nature.com/ reprintsandpermissions/

How to cite this article: Gruszka, D. T. et al. Cooperative folding of intrinsically disordered domains drives assembly of a strong elongated protein. Nat. Commun. 6:7271 doi: $10.1038 /$ ncomms8271 (2015)

(c) (i) This work is licensed under a Creative Commons Attribution 4.0 cc) International License. The images or other third party material in this article are included in the article's Creative Commons license, unless indicated otherwise in the credit line; if the material is not included under the Creative Commons license, users will need to obtain permission from the license holder to reproduce the material. To view a copy of this license, visit http://creativecommons.org/licenses/by/4.0/ 